\title{
LONG-TERM EFFECTIVENESS OF FIRST-LINE ANTIRETROVIRAL THERAPHY IN A COHORT OF HIV-1 INFECTED PATIENTS
}

Departament de Medicina / Universitat Autònoma de Barcelona Autor: Jordi Navarro i Mercadé Director del treball: Manuel Crespo Casal Treball de recerca (convocatòria juny 2012) 


\section{Annex 1}

\section{CERTIFICAT DEL DIRECTOR O CO-DIRECTOR DEL TREBALL DE RECERCA}

Manuel Crespo Casal, metge especialista adjunt del Servei de Malalties Infeccioses del Departament de Medicina Interna de l'Hospital Universitari de la Vall d'Hebron,

\section{FA CONSTAR,}

que el treball titulat "Long-term effectiveness of first-line antiretroviral theraphy in a cohort of HIV-1 infected patients" ha estat realitzat sota la meva direcció pel llicenciat Jordi Navarro i Mercadé, trobant-se en condicions de poder ser presentat com a treball d'investigació de 12 crèdits, dins el programa de doctorat en Medicina Interna/Diagnòstic per la Imatge (curs 20112012), a la convocatòria de juny.

A Barcelona, 14 de maig de dos mil dotze. 


\section{ÍNDEX}

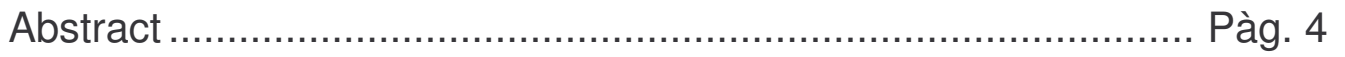

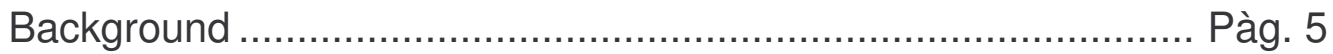

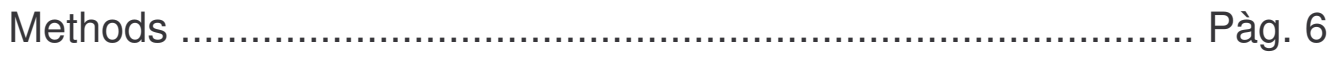

Study Design and Patients ............................................... Pàg. 7

Statistical analysis ........................................................ Pàg. 8

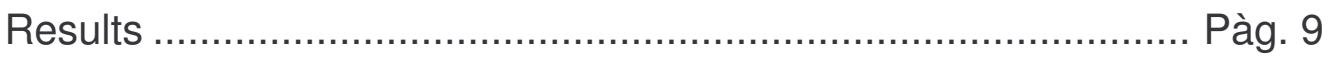

Treatment outcome …..................................................... Pàg. 10

Emergence of drug resistance ........................................... Pàg. 11

Tolerance and safety ………………………………....... Pàg. 11

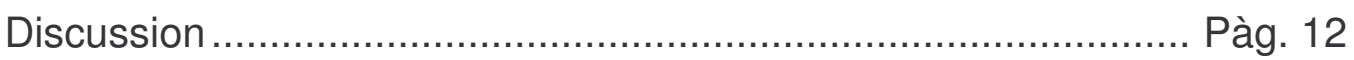

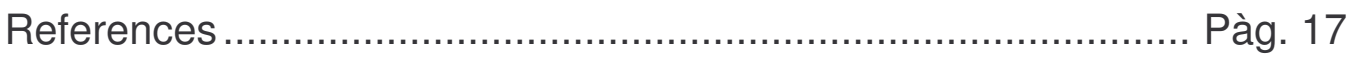

Tables and figures ……………………………….............. Pàg. 25 


\section{ABSTRACT}

\section{Background:}

Eligibility criteria might explain differences in viral response to combined antiretroviral treatment (cART) between clinical trials and routine care setting. Our aim was to assess the effectiveness of CART and factors associated to therapeutic failure (TF) in real clinical conditions.

\section{Methods:}

A prospective cohort analysis including HIV-1 infected patients who started a cART between January 2004 and December 2009, at Vall d'Hebron Hospital. Effectiveness was evaluated as time to TF defined as the first of either virologic failure, treatment discontinuation whatever the reason other than switching, loss to follow-up, or death. The Kaplan-Meier method was used to estimate time-toevent distributions and Cox regression modelling to identify factors associated with TF.

\section{Results:}

We analyzed 232 patients; median CD4+ cell count was 229 cells $/ \mathrm{mm}^{3}$ and median viral load $4.89 \log _{10}$. Almost a third of patients was co-infected with HCV and/or HBV. Tenofovir plus lamivudine/emtricitabine (67\%) was the commonest backbone, and efavirenz (77\%) the preferred third drug. The proportion of patients with no TF at month 12, 24 and 36 was $82.9 \%, 78.5 \%$ and $76 \%$ respectively. TF occurred in $57(24.6 \%)$ patients, mainly due to intolerance or toxicity. The risk of TF was higher in patients starting cART before 2006 and in those with a protease inhibitor based regimen. 


\section{Conclusions:}

After a median follow-up of 36.5 months, three-fourth of patients who started first-line cART remained free of TF. Treatment discontinuation stands as the leading cause of TF. 


\section{BACKGROUND}

Since the introduction of combined antiretroviral treatment (cART) a sustained efficacy improvement has been observed over time in randomized clinical trials (RCT). In recent RCT, by intent-to-treat analyses, $70 \%$ to over $80 \%$ of patients achieved viral suppression to $<50$ copies $/ \mathrm{mL}$ at week 48 of treatment ${ }^{1-5}$, and over $80 \%$ of patients who remain on treatment are able to maintain undetectable viral load for as long as three to seven years ${ }^{6 ; 7}$. However, eligibility criteria to enrol patients in RCT limits the extrapolation of results obtained to routine care setting ${ }^{8}$. Scarce data is available comparing treatment response in RCT (efficacy) versus routine care (effectiveness). In a recent report, although differences did not reach statistical significance, the risk of viral failure at month 12 of treatment was $67 \%$ for routine care patients versus $73 \%$ in those enrolled in RCT, which supposed a $77 \%$ higher risk among patients in routine care (OR $1.77 ; 95 \% \mathrm{Cl} 0.98-3.23)^{8}$. It is important to assess the effectiveness of cART in non selected patients and the durability of treatment response, the main goal of therapy. Furthermore, treatment failure is a good indicator of the quality of patient care and allows the identification of factors associated with treatment failure (TF) in clinical practice.

In the present study, we assess the effectiveness of cART in real clinical conditions and try to identify which factors are associated with treatment outcome. A better understanding of the reasons leading to TF might be useful to improve long-term viral response to the first-line of cART. 


\section{METHODS}

\section{Study Design and Patients:}

A cohort analysis including all consecutive HIV-1 infected patients who started a combined antiretroviral regimen (cART), for the first time between January 2004 and December 2009 at Vall d'Hebron Hospital in Barcelona.

Data was prospectively collected in an electronic-stored case record form, specifically developed for the management of the cohort data (АСуH). In this application demographic data; HIV risk factors; Centers of Disease Control and Prevention (CDC) stage according to 1993 definitions; initiation and stopping data of every single drug used; HIV-1 treatment initiation date; specific antiretroviral regimens used; the date and the reasons for treatment change; causes of death, CD4 cell counts, plasma HIV-RNA levels as evaluated by the NASBA method Nuclisens EasyQ HIV-1 (Biomerieux®, Marcy l'Etoile, France); lower limit of detection changed over time: from 80 to 50 copies $/ \mathrm{mL}$ during 2004 and since then until study closure, 50 copies $/ \mathrm{ml}$, blood cell counts and blood chemistry test data is recorded at each patient visit. In our cohort, patients are periodically evaluated 1 to 3 months following the initiation of ART and then every 3 to 6 months. Adherence was evaluated by self-reported direct questioning and recorded as yes or no.

A nurse-coordinated programme to strengthen patient's adherence, including close follow-up of patients at higher risk for poor adherence (mental disturbances, drug abuse, etc) as well as measures to engage patient in care (i.e. patients missing a laboratory or clinical appointment are contacted by telephone call) was implemented in our Unit at the beginning of study period. 
Resistance testing was systematically performed at baseline since January 2007, following guidelines advice, and in case of viral failure, using the VircoTYPE HIV1 test (Virco BVBA, Mechelen, Belgium) from 2004-2006 and thereafter the TRUGENE HIV-1 genotiping Kit (Siemens Healthcare Diagnostics, Tarrytown NY, USA). Drug resistance-associated mutations (RAMs) were considered as defined by the International AIDS Society-USA guidelines $^{9}$.

Effectiveness of treatment was evaluated as time to treatment failure (TF), using a modified intent-to treat (ITT) analysis that considered as TF any of the following events: virologic failure; treatment change or discontinuation whatever the reason other than switching; loss to follow-up or death. Patients who changed therapy because of simplicity aim or concerns about long-term toxicity had data censored at the switching time. Virologic failure was defined as never achieving a plasma viral load $<200$ copies $/ \mathrm{mL}$ or having a viral load $>200$ copies/mL after treatment week 24 in two consecutive determinations ${ }^{10 .}$ For this analysis, time was 0 days for patients never achieving a plasma viral load $<200$ copies/mL. An additional on-treatment (OT) approach was performed as a sensitivity analysis of efficacy, considering virologic failure as the only imputable cause of TF. Causes of treatment failure; rate of patients with $<50$ copies $/ \mathrm{ml}$ at weeks 48 and 96 of treatment with the first cART regimen, and the rate of patients with $<50$ copies $/ \mathrm{ml}$ at the time of administrative study closure in June 2011, irrespective of the number of cART regimen used, were included as secondary endpoints. 
Patients' follow-up was right-censored at the last available data regardless of the efficacy end point. Informed consent was obtained from every patient, before including all the information into our data base.

\section{Statistical analysis:}

Categorical variables were described as number (proportion) and continuous variables as median (IQR, interquartile range) at least otherwise specified. Student's-T test for paired data was used for related quantitative variables and $\chi 2$ test or McNemar test to compare categorical variables.

Distribution of the time to treatment failure was estimated using the KaplanMeier method. Predictors of TF were identified by Cox regression analysis, using a step-forward selection method. Variables with a $P$ value $\leq 0.1$ were retained in the regression equation. Relative risks are expressed as hazard ratios and $95 \%$ confidence intervals

SPSS software for Windows (Version 15.0; SPSS, Chicago, IL) was used for statistical analyses.

\section{RESULTS}

Demographics and baseline characteristics of the 232 patients evaluated are summarized in Table 1. Median CD4+ cell count was 229 cells $/ \mathrm{mm} 3,35 \%$ of patients had an advanced infection (CD4+ $<200$ cells/mm3) and $14.7 \%$ had a previously AIDS-defining event; median HIV RNA was $4.89 \log _{10}$ and $43 \%$ of patients had $>5 \log _{10}$ at treatment start.

Regarding the initial CART regimen, tenofovir (TDF) plus lamivudine/ emtricitabine (3TC/FTC) $(67 \%)$ or abacavir $(\mathrm{ABC})$ plus $3 \mathrm{TC}(15 \%)$ were the most common backbones (Table 2). Concerning the third drug, a NNRTI was 
selected in 191 subjects (82.3\%), mainly efavirenz (EFV) ( $n=179 ; 77.2 \%)$, as compared to $39(16.8 \%)$ subjects who started a PI-containing regimen. Patients starting a Pl-based regimen had a lower CD4 cell count, $187 \mathrm{cell} / \mathrm{mm}^{3}$, as compared to those starting with a NNRTI, $244 \mathrm{cell} / \mathrm{mm}^{3}(P=0.024)$.

A triple NRTI combination was used in only $2(0.9 \%)$ patients (Table 2$)$.

\section{Treatment outcome:}

After a median follow-up of 36.5 months (IQR, 24.8-50.2), the cumulative proportion of patients remaining free of therapeutic failure was $76 \%(95 \% \mathrm{Cl}$, 70.3-81.7). Corresponding data at treatment month 12, 24 of treatment were $82.9 \%(95 \% \mathrm{Cl}, 78-87.8)$ and $78.5 \%(95 \% \mathrm{Cl}, 73-84)$, respectively (Figure 1). Corresponding figures by on treatment analysis were $97 \%(95 \% \mathrm{Cl}, 94.6-99.3)$, 95.3\% (95\%Cl, 92.4- 98.2) and 93.7\% (95\%Cl, 90.0-97.4) at month 12, 24 and 36 of treatment, respectively. Treatment failure was observed in $57(24.6 \%)$ patients, mainly due to intolerance or toxicity (13\%) (Table 3). True virological failure was observed in $13(5.6 \%)$ patients and occurred at median treatment time of 7.0 months $(95 \% \mathrm{Cl}, 2.1-14.8)$.

Starting cART in 2004-2005 vs. starting in 2006-2009, co-infection with HCV and/or HBV and starting a PI-based regimen were associated with a higher likelihood of therapeutic failure by univariate Cox's regression analysis. On the other hand, demographic data, risk factor for HIV acquisition or pre-treatment availability of genotypic resistance test were not associated to treatment outcome. In a multivariate model, starting cART before 2006 and using a PIbased regimen, were independently associated with a higher risk of TF. 
Furthermore, a trend for a higher risk for TF was observed among patients coinfected with HVC and/or HBV (Table 4).

A significant mean increase in CD4+ cell count, 209 cells $/ \mathrm{mm}^{3}(95 \% \mathrm{Cl}, 186-$ 232) was observed at week 48 of treatment. At the end of follow-up the number of patients with CD4 above 350 cells $/ \mathrm{mm}^{3} \quad(\mathrm{n}=189 ; 81.5 \%)$ significantly increased as compared to baseline $(n=23 ; 9.9 \%)(p<0.001)$. No baseline variable, including demographic data, starting a PI-based vs. NNRTI-based regimen or HCV and/or HBV status, was significantly associated with CD4+ cell counts change.

At the end of follow-up, considering missing data as treatment failure and regardless of the primary efficacy end point and the number of cART regimens used, 208 (90\%) out of 232 patients had HIV RNA $<50 \mathrm{cop} / \mathrm{ml}$.

\section{Emergence of drug resistance:}

A genotypic resistance test was performed in 9 of the 13 patients who experienced virological failure. Overall, the emergence of resistance-associated mutations (RAMs) occurred in 1 of 39 patients (25.6\%) who started a PI-based regimen as compared to 5 of 191 patients $(26.2 \%)$ on a NNRTI-based regimen (risk ratio $=0.98 ; 95 \% \mathrm{Cl}, 0.12-8.15)$.

\section{Tolerance and safety:}

Median duration of first line regimen was 29.0 months (IQR, 13.5-40.3). Intolerance or toxicity $(12.9 \%)$, followed by switching $(8.2 \%)$, were the main causes of treatment change or discontinuation of the initial antiretroviral regimen. (Table 3) 
Main adverse events leading to therapeutic change were EFV-associated neurological toxicity and skin rash (Table 3). There were no grade 3-4 adverse events and only 2 patients $(0.86 \%)$ presented hypersensitivity reaction to $A B C$.

During the study period, 69 (29.7\%) and 20 (8.6\%) patients received 2 and $\geq 3$ different ART regimens, respectively. Main causes for change of the secondline CART were: intolerance/toxicity (10 patients), switch (7 cases), virologic failure (2 cases) and pregnancy ( 1 patient). Eleven (4.7\%) patients were lost to follow-up. Overall, $4(1.7 \%)$ patients died, 3 of them under the initial ART regimen. Causes of death were, each one, primary cerebral lymphoma, Kaposi's Sarcoma and laryngeal and lung neoplasias.

\section{DISCUSSION}

The effectiveness of currently used first-line cART regimens have increased substantially, greatly reducing the likelihood of initial regimen failure in conditions of clinical practice ${ }^{11}$. In our study, over three-fourth of patients who started cART from 2004 to 2009 remained free of therapeutic failure to the firstline regimen, after a median follow-up of 36.5 months. The effectiveness of cART in our population is similar to efficacy data reported from recently conducted RCT. Indeed, considering the overall population, irrespective of therapeutic changes for whichever reason $(30 \%$ and $9 \%$ of patients received 2 and $\geq 3$ different regimens, respectively) almost $90 \%$ of patients who started cART in our cohort had viral suppression to less than 50 copies $/ \mathrm{mL}$ at the end of follow up.

Despite advances in antiretroviral treatment, as reflected by the excellent treatment outcome of our cohort, some patients do not respond optimally to 
first-line therapy and a variety of reasons account for TF. In our study, the risk of TF was higher among patients starting CART before 2006 and those who received a PI-based regimen. Furthermore, a trend for a worse treatment outcome was observed among HCV and/or HVB co-infected patients. Poor tolerance to $\mathrm{Pl} / \mathrm{r}$ and poor tolerated or less convenient regimens formerly used in our cohort, which might be particularly relevant in co-infected patients ${ }^{12}$, are the most likely mechanisms resulting in TF among these patients.

In agreement with previous studies ${ }^{13-16}$, in our cohort treatment discontinuation was the main cause for regimen failure.

The improvement of the toxicity profile of currently used NRTI as compared to thymidine-analogues and the better convenience of fixed-drug combinations, by improving tolerance and adherence, contributes to explain the high efficacy rates observed with contemporary used regimens both in RCT ${ }^{5 ; 17-19}$ and cohort studies ${ }^{20 ; 21}$. In keeping with these data, in the present study, TDF plus 3 TC/FTC was the most used NRTI combination (67\%) followed by ABC plus 3TC (15\%), which represents an excellent backbone option in patients who test negative for HLA-B*5701 ${ }^{22}$, although a higher rate of viral failure may occur in patients with high pre-treatment viral load $>100.000 \mathrm{cop} / \mathrm{ml}^{5}$. Conversely, few patients $(8.1 \%)$ started a thymidine-analogue containing regimen or a ddlincluding regimen.

Furthermore, during the study, the thymidine-analogue was discontinued because toxicity or intolerance $(n=4)$ or was proactively switched to a more convenient or less toxic NRTI $(n=18)$. Early switch in order to minimize the risk of side effects and long-term toxicity or to improve convenience may be useful to support adherence and to increase long-term viral suppression ${ }^{6: 18}$. 
As a third drug, EFV was preferentially used in $77 \%$ of patients, which could contribute to explain the high rate of therapeutic success. EFV is a well tolerated, convenient and potent drug that has demonstrated a durable viral suppression in large RCT ${ }^{18 ; 23}$. Furthermore, EFV-based regimens have never been found to be inferior to any other third-drug strategy, triple NRTI ${ }^{24 ; 25}$; other NNRTI ${ }^{26-28}$; PI-based regimens ${ }^{29 ; 30}$ or new viral target drugs such as raltegravir ${ }^{31}$ or maraviroc ${ }^{32}$. Nevirapine, may be a valid alternative to EFV ${ }^{26 ; 33}$, mainly in pregnancy or when neurologic toxicity might be a concern ${ }^{22}$. In these events, CD4+ cell counts restrictions must be considered to minimize the risk of hypersensitivity to NEV ${ }^{34 ; 35}$.

In contrast with data from a large multicentre European unselected cohort ${ }^{36}$, high viral load or low pre-treatment CD4 cells counts were not associated with a higher risk of virologic failure in our study. In fact, none of the variables was independently associated with treatment outcome, which could be in relation with the large number of patients who started a TDF plus 3TC/FTC and EFV regimen ${ }^{37}$.

The incidence of high-level drug resistance has fallen over time following the introduction of cART for first-line therapy. In the EuroSIDA cohort, the incidence of triple-class failure over 5 years among patients who started a 3-drug HAART was $4.8 \%$ compared with $15.5 \%$ for patients who started on NRTI monotherapy or dual NRTI therapy before receiving HAART regiments ${ }^{38}$. In our study, only 13 patients (5.6\%) experienced true virologic failure, and no differences were seen in the number of patients who developed RAMs between PIs and NNRTIbased regimens, probably because of the small size of the cohort. 
Some limitations of this study are to be mentioned. First of all, because the limited cohort sample size we are not able to confidently compare the effectiveness and the risk of drug resistance at viral failure between NNRTI and PI-based regimens; the differences in effectiveness among different Pls or different backbone combinations. In addition, very few patients received atazanavir and no patient was on darunavir during the study period, considered to be a preferred PI for naïve patients in current treatment guidelines ${ }^{10 ; 22}$. Also, genotypic resistance test at baseline was only available in $34.5 \%$ of patients $(n=80)$, which could have a negative impact on patients starting a NNRTI-based regimen. However, treatment outcome was not associated with pre-treatment genotype assessment. Additionally, the number of patients who could be analyzed for genotype at viral failure was low. Finally, our data provides from a single centre and extrapolation to different populations should be cautiously made. An analysis of multisite cohort collaborations may be useful to evaluate this point. Nevertheless, demographic and clinical characteristics of patients at baseline are similar to that reported in other studies conducted in Spain ${ }^{39}$ and the South of Europe ${ }^{40}$.

In summary, after a median follow-up of three years, three-fourth of patients who started a CART remained free of therapeutic failure. Treatment discontinuations because of intolerance/side effects or lost to follow up stands as the leading cause of therapeutic failure, which strengthens the importance of strategies addressed to optimize patient's compliance. Simplicity and better toxicity profile of newer regimens, as well as additional measures to retain patients in care contribute to improve adherence and to achieve long-term virologic suppression in routine clinical setting, as suggested by the high 
proportion of patients, $90 \%$, who achieved viral suppression to less than 50 copies $/ \mathrm{ml}$ at the end of follow-up. 


\section{References}

(1) Eron J, Jr., Yeni $P$, Gathe J, Jr. et al.: The KLEAN study of fosamprenavir-ritonavir versus lopinavir-ritonavir, each in combination with abacavir-lamivudine, for initial treatment of HIV infection over 48 weeks: a randomised non-inferiority trial. Lancet 2006; 368(9534):476482.

(2) Molina JM, Andrade-Villanueva $J$, Echevarria $J$ et al.: Once-daily atazanavir/ritonavir versus twice-daily lopinavir/ritonavir, each in combination with tenofovir and emtricitabine, for management of antiretroviral-naive HIV-1-infected patients: 48 week efficacy and safety results of the CASTLE study. Lancet 2008; 372(9639):646-655.

(3) Ortiz R, Dejesus E, Khanlou $\mathrm{H}$ et al.: Efficacy and safety of once-daily darunavir/ritonavir versus lopinavir/ritonavir in treatment-naive HIV-1infected patients at week 48. AIDS 2008; 22(12):1389-1397.

(4) Walmsley S, Avihingsanon A, Slim J et al.: Gemini: a noninferiority study of saquinavir/ritonavir versus lopinavir/ritonavir as initial HIV-1 therapy in adults. J Acquir Immune Defic Syndr 2009; 50(4):367-374.

(5) Sax PE, Tierney C, Collier AC et al.: Abacavir-lamivudine versus tenofovir-emtricitabine for initial HIV-1 therapy. N Engl J Med 2009; 361(23):2230-2240 
(6) Arribas JR, Pozniak AL, Gallant JE et al.: Tenofovir disoproxil fumarate, emtricitabine, and efavirenz compared with zidovudine/lamivudine and efavirenz in treatment-naive patients: 144-week analysis. $\mathrm{J}$ Acquir Immune Defic Syndr 2008; 47(1):74-78.

(7) Murphy RL, da Silva BA, Hicks CB et al.: Seven-year efficacy of a lopinavir/ritonavir-based regimen in antiretroviral-naive HIV-1-infected patients. HIV Clin Trials 2008; 9(1):1-10.

(8) Routman JS, Willig JH, Westfall AO et al.: Comparative efficacy versus effectiveness of initial antiretroviral therapy in clinical trials versus routine care. Clin Infect Dis 2010; 50(4):574-584.

(9) Johnson VA, Brun-Vezinet F, Clotet B et al.: Update of the drug resistance mutations in HIV-1: December 2010. Top HIV Med 2010; 18(5):156-163.

(10) Guidelines for treating HIV-infected adults and adolescents, including utilization of resistance testing, initiation of treatment, preferred first-line regimens, adverse events to antiretroviral medications, managing treatment-experienced patients, and considerations for special populations [release October 2011]. Available at: http://aidsinfo.nih.gov/contentfiles/AdultandAdolescentGL.pdf. Accessed (February, 15th 2012). 
(11) Moore RD, Keruly JC, Gebo KA, Lucas GM: An improvement in virologic response to highly active antiretroviral therapy in clinical practice from 1996 through 2002. J Acquir Immune Defic Syndr 2005; 39(2):195-198.

(12) Cooper CL, Mills E: Comparison of first antiretroviral treatment duration and outcome in HIV, HIV-HBV and HIV-HCV infection. Int J STD AIDS $2007 ; 18(8): 546-550$.

(13) Gratacos L, Tuset M, Codina C et al.: [Antiretroviral therapy of HIV infection: duration and reasons for changing the first therapeutic regimen in 518 patients]. Med Clin (Barc ) 2006; 126(7):241-245.

(14) Dorrucci M, Pezzotti P, Grisorio B et al.: Time to discontinuation of the first highly active antiretroviral therapy regimen: a comparison between protease inhibitor- and non-nucleoside reverse transcriptase inhibitorcontaining regimens. AIDS 2001; 15(13):1733-1736.

(15) Chen RY, Westfall AO, Mugavero MJ et al.: Duration of highly active antiretroviral therapy regimens. Clin Infect Dis 2003; 37(5):714-722.

(16) Cicconi P, Cozzi-Lepri A, Castagna A et al.: Insights into reasons for discontinuation according to year of starting first regimen of highly active antiretroviral therapy in a cohort of antiretroviral-naive patients. HIV Med 2010; 11(2):104-113. 
(17) Gallant JE, Dejesus E, Arribas JR et al.: Tenofovir DF, emtricitabine, and efavirenz vs. zidovudine, lamivudine, and efavirenz for HIV. N Engl J Med 2006; 354(3):251-260.

(18) Gallant JE, Staszewski S, Pozniak AL et al.: Efficacy and safety of tenofovir DF vs stavudine in combination therapy in antiretroviral-naive patients: a 3-year randomized trial. JAMA 2004; 292(2):191-201.

(19) Riddler SA, Haubrich R, DiRienzo AG et al.: Class-sparing regimens for initial treatment of HIV-1 infection. N Engl J Med 2008; 358(20):20952106.

(20) Gill VS, Lima VD, Zhang W et al.: Improved virological outcomes in British Columbia concomitant with decreasing incidence of HIV type 1 drug resistance detection. Clin Infect Dis 2010; 50(1):98-105.

(21) Das M, Chu PL, Santos GM et al.: Decreases in community viral load are accompanied by reductions in new HIV infections in San Francisco. PLoS One 2010; 5(6):e11068.

(22) Documento de consenso de GESIDA/Plan nacional sobre el sida respecto al tratamiento antirretroviral en adultos infectados por el virus de inmunodeficiencia humana [actualizado enero 2011]. Available at: http://www.gesida.seimc.org/pcientifica/fuentes/dcyrc/gesidadcyrc2011documentoconsenso-tar-adulto-verordenador.pdf. (February, 15th 2012). 
(23) Gulick RM, Ribaudo HJ, Shikuma CM et al.: Three- vs four-drug antiretroviral regimens for the initial treatment of HIV-1 infection: a randomized controlled trial. JAMA 2006; 296(7):769-781.

(24) Gulick RM, Ribaudo HJ, Shikuma CM et al.: Triple-nucleoside regimens versus efavirenz-containing regimens for the initial treatment of HIV-1 infection. N Engl J Med 2004; 350(18):1850-1861.

(25) Gallant JE, Rodriguez AE, Weinberg WG et al.: Early virologic nonresponse to tenofovir, abacavir, and lamivudine in HIV-infected antiretroviral-naive subjects. J Infect Dis 2005; 192(11):1921-1930.

(26) van LF, Phanuphak P, Ruxrungtham $\mathrm{K}$ et al.: Comparison of first-line antiretroviral therapy with regimens including nevirapine, efavirenz, or both drugs, plus stavudine and lamivudine: a randomised open-label trial, the 2NN Study. Lancet 2004; 363(9417):1253-1263.

(27) Cohen CJ, Andrade-Villanueva J, Clotet B et al.: Rilpivirine versus efavirenz with two background nucleoside or nucleotide reverse transcriptase inhibitors in treatment-naive adults infected with HIV-1 (THRIVE): a phase 3, randomised, non-inferiority trial. Lancet 2011; 378(9787):229-237.

(28) Molina JM, Cahn P, Grinsztejn B et al.: Rilpivirine versus efavirenz with tenofovir and emtricitabine in treatment-naive adults infected with HIV-1 
(ECHO): a phase 3 randomised double-blind active-controlled trial. Lancet 2011; 378(9787):238-246.

(29) Riddler SA, Haubrich R, DiRienzo AG et al.: Class-sparing regimens for initial treatment of HIV-1 infection. N Engl J Med 2008; 358(20):20952106.

(30) Squires K, Lazzarin A, Gatell JM et al.: Comparison of once-daily atazanavir with efavirenz, each in combination with fixed-dose zidovudine and lamivudine, as initial therapy for patients infected with HIV. J Acquir Immune Defic Syndr 2004; 36(5):1011-1019.

(31) Lennox JL, Dejesus E, Lazzarin A et al.: Safety and efficacy of raltegravir-based versus efavirenz-based combination therapy in treatment-naive patients with HIV-1 infection: a multicentre, double-blind randomised controlled trial. Lancet 2009; 374(9692):796-806.

(32) Cooper DA, Heera J, Goodrich J et al.: Maraviroc versus efavirenz, both in combination with zidovudine-lamivudine, for the treatment of antiretroviral-naive subjects with CCR5-tropic HIV-1 infection. J Infect Dis 2010; 201(6):803-813.

(33) Soriano V, Arasteh K, Migrone $\mathrm{H}$ et al.: Nevirapine versus atazanavir/ritonavir, each combined with tenofovir disoproxil fumarate/emtricitabine, in antiretroviral-naive HIV-1 patients: the ARTEN Trial. Antivir Ther 2011; 16(3):339-348. 
(34) Sanne I, Mommeja-Marin H, Hinkle $J$ et al.: Severe hepatotoxicity associated with nevirapine use in HIV-infected subjects. J Infect Dis 2005; 191(6):825-829.

(35) Baylor MS, Johann-Liang R: Hepatotoxicity associated with nevirapine use. J Acquir Immune Defic Syndr 2004; 35(5):538-539.

(36) Paredes R, Mocroft A, Kirk O et al.: Predictors of virological success and ensuing failure in HIV-positive patients starting highly active antiretroviral therapy in Europe: results from the EuroSIDA study. Arch Intern Med 2000; 160(8):1123-1132.

(37) Daar ES, Tierney C, Fischl MA et al.: Atazanavir plus ritonavir or efavirenz as part of a 3-drug regimen for initial treatment of HIV-1. Ann Intern Med 2011; 154(7):445-456.

(38) Wittkop L, Gunthard HF, de WF et al.: Effect of transmitted drug resistance on virological and immunological response to initial combination antiretroviral therapy for HIV (EuroCoord-CHAIN joint project): a European multicohort study. Lancet Infect Dis 2011; 11(5):363-371 .

(39) Centro Nacional de Epidemiología. Vigilancia epidemiológica del VIH en España. Nuevos diganósticos de VIH en España. Periodo 2003-2009. Actualización a 30 de junio de 2010. Available at: www.isciii.es. (February, 15th 2012). 
(40) Bonnet F, Thiebaut R, Chene $G$ et al.: Determinants of clinical progression in antiretroviral-naive HIV-infected patients starting highly active antiretroviral therapy. Aquitaine Cohort, France, 1996-2002. HIV Med 2005; 6(3):198-205. 
Table 1. Baseline characteristics of 232 patients analyzed

\begin{tabular}{|c|c|}
\hline Variable & Value \\
\hline Age, years (IQR) & $33.5(28-41.8)$ \\
\hline Sex male, n (\%) & $175(75.4 \%)$ \\
\hline $\begin{array}{l}\text { Ethnic origin, } \mathrm{n}(\%) \\
\text { White } \\
\text { Hispanic } \\
\text { Asian } \\
\text { African }\end{array}$ & $\begin{array}{c}168(72.4 \%) \\
44(19 \%) \\
3(1.3 \%) \\
17(7.3 \%)\end{array}$ \\
\hline $\begin{array}{l}\text { Risk factor for HIV acquisition, n (\%) } \\
\text { Heterosexual } \\
\text { Homosexual/bisexual } \\
\text { IDU } \\
\text { Other/Unknown }\end{array}$ & $\begin{array}{c}101(43.5 \%) \\
89(38.4 \%) \\
35(15.1 \%) \\
7(3 \%)\end{array}$ \\
\hline HCV-coinfection, n (\%) & $59(25.4 \%)$ \\
\hline HBV-coinfection, n (\%) & $13(5.6 \%)$ \\
\hline Time since HIV diagnosis, months (IQR) & $14.6(3.1-34.8)$ \\
\hline $\begin{array}{l}\text { Starting HAART year, n (\%) } \\
2004-2005 \\
2006-2007 \\
2008-2009\end{array}$ & $\begin{array}{c}51(22 \%) \\
82(35.3 \%) \\
99(42.6 \%)\end{array}$ \\
\hline $\begin{array}{l}\text { CD4 cell count at HAART initiation, } \\
\text { median cell/mm³ (IQR) } \\
\quad<50, \mathrm{n}(\%) \\
50-199 \\
200-349 \\
\geq 350\end{array}$ & $\begin{array}{l}229(160-289) \\
21(9.1 \%) \\
60(25.9 \%) \\
128(55.2 \%) \\
23(9.9 \%)\end{array}$ \\
\hline $\begin{array}{l}\text { Viral load }\left(\log _{10}\right), \text { median (IQR) } \\
>100.000 \mathrm{cop} / \mathrm{ml}, \mathrm{n}(\%)\end{array}$ & $\begin{array}{c}4.89(4.34-5.38) \\
100(43.1 \%)\end{array}$ \\
\hline
\end{tabular}

Table 1 footnotes

IDU, intravenous drug user; HCV, hepatitis $\mathrm{C}$ virus; HBV, hepatitis $B$ virus; HAART, high activity antiretroviral treatment 
Table 2. Antiretroviral combinations used as a first-line regimen.

\begin{tabular}{|c|c|c|c|c|c|c|c|}
\hline \multirow[t]{2}{*}{ Backbone } & \multicolumn{6}{|c|}{ Third drug-based cART } & \multirow[t]{2}{*}{ Overall } \\
\hline & Efavirenz & Nevirapina & Lopinavir/r & Atazanavir/r & Fosamprenavir/r & Saquinavir/r & \\
\hline TDF+FTC/3TC & $132(56.9 \%)$ & $3(1.3 \%)$ & $7(3 \%)$ & $5(2.1 \%)$ & $4(1.7 \%)$ & $4(1.7 \%)$ & $155(66.8 \%)$ \\
\hline$A B C+3 T C$ & $22(9.5 \%)$ & $2(0.8 \%)$ & $1(0.4 \%)$ & $4(1.7 \%)$ & $4(1.7 \%)$ & $1(0.4 \%)$ & $34(14.7 \%)$ \\
\hline $\mathrm{AZT}+3 \mathrm{TC}$ & $7(3 \%)$ & $5(2.1 \%)$ & $3(1.3 \%)$ & - & $1(0.4 \%)$ & - & $16(6.8 \%)$ \\
\hline ddl+3TC & $15(6.5 \%)$ & $2(0.8 \%)$ & $1(0.4 \%)$ & $3(1.3 \%)$ & - & $1(0.4 \%)$ & $22(9.5 \%)$ \\
\hline d4T+3TC & $3(1.3 \%)$ & - & - & - & - & - & $3(1.3 \%)$ \\
\hline Overall & $179(77.2 \%)$ & $12(5.2 \%)$ & $12(5.2 \%)$ & $12(5.2 \%)$ & $9(3.8 \%)$ & $6(2.5 \%)$ & $230(99.1 \%)^{1}$ \\
\hline
\end{tabular}

Table 2 footnotes

1. Two additional patients (0.9\%) started a regimen based on AZT plus $3 T C$ and $\mathrm{ABC}$

ABC, abacavir; AZT, zidovudine; CART: combined antiretroviral treatment ; ddl. didanosine; d4T. Stavudine; FTC, Emtricitabine; IDU, intravenous drug user; 3TC, lamivudine; R, ritonavir-boosted; TDF, tenofovir 
Table 3. Causes of discontinuation of the initial antiretroviral regimen

\begin{tabular}{|ll|}
\hline \multicolumn{1}{|c|}{ Causes } & \multicolumn{1}{c|}{ Value (\%) } \\
\hline Overall & $83(35.8)$ \\
\hline Switch & $19(8.2)$ \\
\hline Pregnancy & $6(2.6)$ \\
\hline Drug-drug interaction & $1(0.4)$ \\
\hline Therapeutic failure & \\
\hline Any & $57(24.6)$ \\
\hline Intolerance/Side effects & $30(12.9)$ \\
\hline Neurological & $11(4.7)$ \\
Hepatotoxicity & $1(<1)$ \\
Nefrotoxicity & $2(<1)$ \\
Gastrointestinal intolerance & $2(<1)$ \\
Skin rash & $9(3.9)$ \\
Metabolic disorder & $1(<1)$ \\
Anemia & $4(1.7)$ \\
\hline Virological failure & $13(5.6)$ \\
\hline Lost to follow up & $11(4.7)$ \\
\hline Death & $3(1.3)$ \\
\hline
\end{tabular}


Table 4. Variables associated with treatment failure as assessed by Cox proportional hazards regression analysis

\begin{tabular}{|c|c|c|c|c|}
\hline & HR (95\%Cl) & $\mathbf{P}$ & HR $95 \% \mathrm{Cl}^{1}$ & $\mathbf{P}^{\mathbf{a}}$ \\
\hline Sex Male vs. female & $0.709(0.414-1.320)$ & 0.307 & & \\
\hline Age $>40$ years vs. $<40$ years & $1.25(.733-2.125)$ & 0.414 & & \\
\hline IDU vs. other transmission group & $1.23(0.640-2.38)$ & 0.540 & & \\
\hline $\begin{array}{l}\text { cART starting year } \\
2004-2005 \text { vs. } 2006-2009\end{array}$ & $1.860(1.066-3.247)$ & 0.029 & $1.807(1.028-3.176)$ & 0.040 \\
\hline $\begin{array}{l}\text { HCV and/or HBV-coinfection vs. } \\
\text { HIV monoinfection }\end{array}$ & $1.976(1.174-3.328)$ & 0.010 & $1.608(0.924-2.797)$ & 0.093 \\
\hline $\begin{array}{l}\text { CD } 4+\text { cell count }<200 / \mathrm{mm}^{3} \text { vs. } \\
>200 / \mathrm{mm}^{3}\end{array}$ & $1.342(0.782-2.302$ & 0.285 & & \\
\hline $\begin{array}{l}\text { HIV RNA > } 100.000 \mathrm{cop} / \mathrm{ml} \text { vs. } \\
<100.000 \mathrm{cop} / \mathrm{ml}\end{array}$ & $0.832(0.489-1.413)$ & 0.496 & & \\
\hline TDF + 3TC/FTC backbone & $0.613(0.362-1.037)$ & 0.068 & & \\
\hline ABC + 3TC backbone & $1.290(0.630-2.650)$ & 0.481 & & \\
\hline $\begin{array}{l}\text { PI vs. NNRTI-based starting } \\
\text { regimen }\end{array}$ & $2.118(1.187-3.779)$ & 0.011 & $1.893(0.1029-3.485)$ & 0.040 \\
\hline
\end{tabular}

Table 4 footnotes

1. A Cox regression analysis, using a step-forward selection method, was performed to indentify variables associated to treatment outcome. Variables with a $P$ value $\leq 0.1$ are retained in the regression equation. Relative risks are expressed as hazard ratios (HR) and $95 \%$ confidence intervals $(\mathrm{Cl})$

ABC, abacavir; AZT, zidovudine; CART: combined antiretroviral treatment; ddl. didanosine; d4T. Stavudine; FTC, Emtricitabine; IDU, intravenous drug user; 3TC, lamivudine; NNRTI, non-nucleosida reverse transcriptase inhibitor; R, ritonavir-boosted; PI, protease inhibitor; TDF, tenofovir 
Figure 1. Cumulative percentage of patients remaining free of therapeutic failure to the first-line regimen

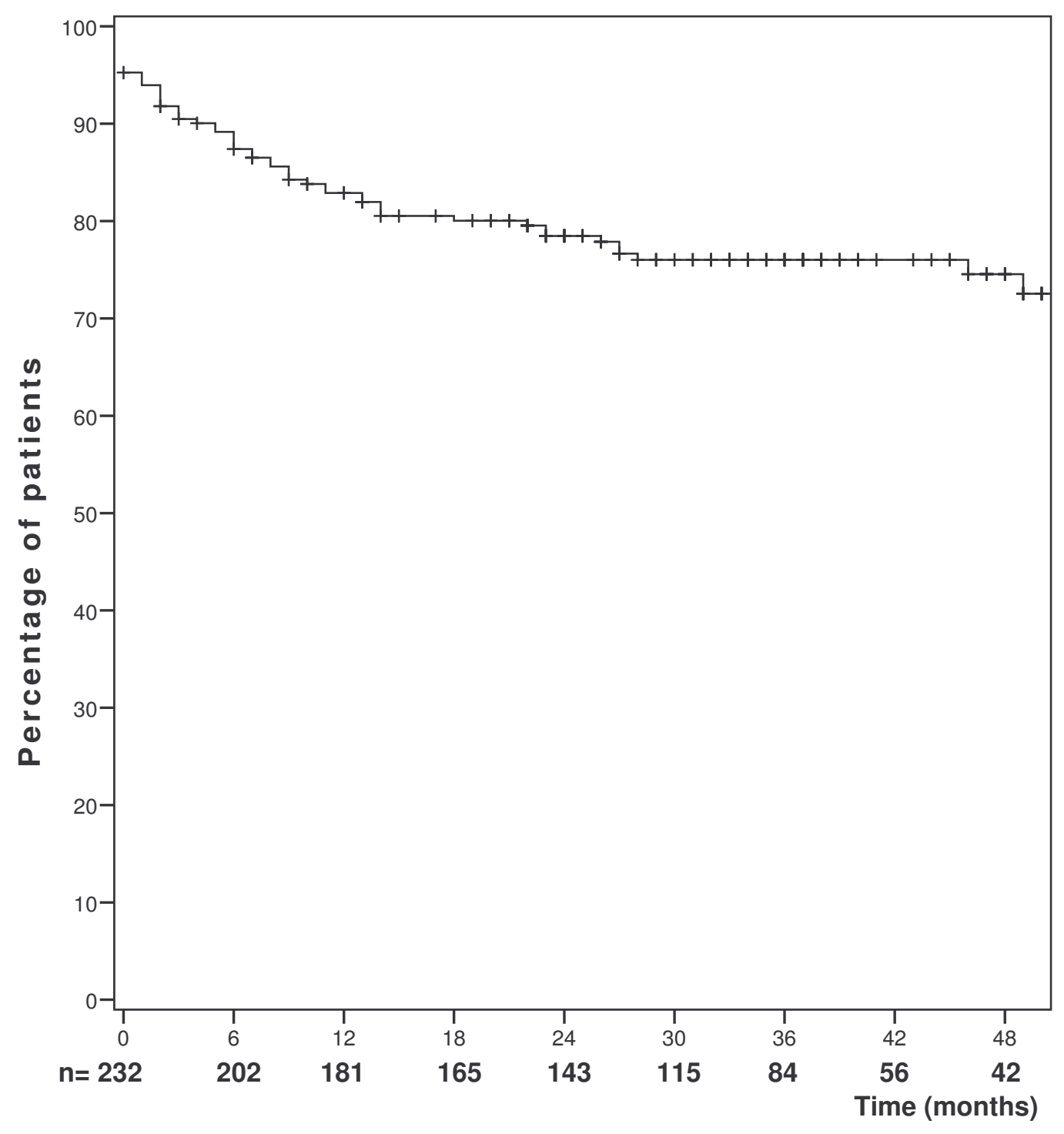

